\title{
Medical management to full recovery in patients with severe ischemic cardiomyopathy
}

\author{
Nicole M. Fesel, Sara Y. Narveson, Sarah L. Marconi, Laszlo Littmann \\ Department of Internal Medicine, Carolinas Medical Center, Charlotte, NC, USA.
}

Correspondence: Laszlo Littmann. Address: Department of Internal Medicine, Carolinas Medical Center, Charlotte, NC 28232, USA. Email: Laszlo.Littmann@carolinashealthcare.org

Received: August 25, 2014

DOI : $10.5430 /$ crim.v2n1p36

\section{Abstract}

The role of coronary artery bypass grafting in the treatment of patients with ischemic cardiomyopathy and heart failure has not been clearly established. A few studies have suggested that patients with multivessel coronary artery disease and severe left ventricular dysfunction may have superior outcomes with surgery than with medical management. In this report we describe three patients with multivessel coronary artery disease, severe ischemic cardiomyopathy and advanced heart failure who experienced full and sustained clinical and echocardiographic recovery with medical management alone, without revascularization. These cases constitute "proof of concept" indicating that aggressive medical management may be an appropriate first-line therapy for such patients.

\section{Keywords}

Ischemic cardiomyopathy, Heart failure, Medical management, Coronary artery bypass surgery, Prognosis

\section{Introduction}

Patients with advanced heart failure (HF), especially those who require hospitalization, generally have poor outcomes with high morbidity and mortality ${ }^{[1]}$. The prognosis is even worse for patients with ischemic rather than nonischemic cardiomyopathy ${ }^{[2]}$. Treatment options in ischemic cardiomyopathy include medical management with or without revascularization. It is uncertain if in addition to medical management, coronary artery bypass grafting (CABG) improves patient outcomes. The purpose of this brief case series is to demonstrate that patients with severe multivessel CAD, very low left ventricular ejection fraction (LVEF) and advanced clinical HF can have full and sustained clinical and echocardiographic recovery with medical management alone, without revascularization.

\section{Case presentation}

Pertinent clinical and echocardiographic findings of 3 selected cases are summarized in Table 1. Each patient had been hospitalized for florid HF with pulmonary and peripheral edema, jugular venous distension and S3 gallop. The echocardiographic LVEF ranged from $10 \%-25 \%$. None of the patients had a clinical history of myocardial infarction but two patients had frank abnormal Q waves in the electrocardiogram and one patient had borderline abnormal Q waves. In all 3 cases, cardiac catheterization demonstrated severe multivessel CAD including case 1 who had $100 \%$ proximal 
occlusion of all 3 major epicardial coronary arteries. In each case, CABG was declined either because of unsuitable coronary anatomy and/or because of poor functional performance status.

Table 1. Pertinent clinical and echocardiographic findings on presentation and at follow-up

\begin{tabular}{|c|c|c|c|}
\hline Case \# & 1 & 2 & 3 \\
\hline Age/Gender & $64 / \mathrm{M}$ & $57 / \mathrm{M}$ & $57 / \mathrm{M}$ \\
\hline Coronary stenoses (\%) & $\begin{array}{l}\text { LAD } 100 \text { ostial } \\
\text { LCX } 100 \text { proximal } \\
\text { RCA } 100 \text { ostial }\end{array}$ & $\begin{array}{l}\text { LAD diffuse } \\
\text { LCX } 70+99 \\
\text { RCA } 100 \text { proximal }\end{array}$ & $\begin{array}{l}\text { LAD } 50 \text { tubular } \\
\text { LAD-D } 190 \text { proximal } \\
\text { LCX } 60 \text { proximal } \\
\text { RCA } 100 \text { proximal }\end{array}$ \\
\hline LVEF on presentation & $10 \%-15 \%$ & $20 \%-25 \%$ & $20 \%$ \\
\hline NYHA on presentation & IV & IV & IV \\
\hline $\begin{array}{l}\text { Duration of therapy until target dose of } \\
\text { beta blocker }\end{array}$ & 5.5 months & 1.5 months & 1.5 months \\
\hline $\begin{array}{l}\text { Duration of therapy until normalization of } \\
\text { LVEF }\end{array}$ & 19 months & 7 months & 4 months \\
\hline LVEF at follow-up & $55 \%-60 \%$ & $56 \%$ & $50 \%-55 \%$ \\
\hline NYHA class at follow-up & I & I & II \\
\hline Clinical recovery at & 12 months & 4 months & 4 months \\
\hline $\begin{array}{l}\text { Continues to be asymptomatic at } \\
\text { follow-up of }\end{array}$ & 8 years & $4 \frac{1}{2}$ years & 4 years \\
\hline
\end{tabular}

Note. Abbreviations: $\mathrm{LAD}=$ left anterior descending coronary artery; $\mathrm{LAD}-\mathrm{D} 1=$ first diagonal branch of the LAD; $\mathrm{LCX}=$ left circumflex coronary artery; $\mathrm{LVEF}=$ left ventricular ejection fraction; $\mathrm{M}=$ male; NYHA = New York Heart Association functional class; RCA = right coronary artery

The patients were enrolled in our multidisciplinary HF disease management program where we provide aggressive outpatient management for patients with advanced systolic heart failure. Our focus is on very early and frequent clinic visits following hospital discharge (every 1-2 weeks initially), intensive patient education, rapid titration of all evidence-based medications and active, bidirectional telephone management. A few months into enrollment, all 3 patients were on maximum tolerated doses of HF medications including maximum doses of beta blockers at 1.5 to 5.5 months. Each patient experienced a dramatic improvement in their clinical status; by 4-12 months into enrollment, they no longer had HF symptoms or significant physical limitation. Repeat echocardiograms at 4-19 months showed normal LVEF in all. Patients continue to be asymptomatic 4 to 8 years later.

\section{Discussion}

The role of revascularization in patients with ischemic cardiomyopathy has not been clearly established. Several decades ago randomized trials have demonstrated improved short-term outcomes with CABG compared to medical management in patients with multivessel CAD and reduced $\mathrm{LVEF}^{[3,4]}$. Those trials, however, enrolled patients with angina and excluded patients with severe HF. Subsequent nonrandomized studies have suggested favorable outcomes with CABG in patients with adverse prognostic indicators ${ }^{[5-7]}$. The STICH trial was the first to compare modern and optimum medical management alone or in combination with CABG in patients with ischemic cardiomyopathy and an LVEF of $\leq 35 \%{ }^{[8]}$. There was no statistically significant difference in the primary end point of the trial although in several secondary end points, patients who were randomized to CABG fared better. Most patients in the STICH trial, however, did not have severe clinical HF, and results of follow-up echocardiograms were not reported ${ }^{[8]}$. The 2013 American College of Cardiology Foundation and American Heart Association guidelines gave class IIa indication both for medical management and for $\mathrm{CABG}$ in patients with severe left ventricular dysfunction, $\mathrm{HF}$, and significant $\mathrm{CAD}^{\left[{ }^{[9]}\right.}$. 
Our case series is interesting in that it demonstrates how powerful medical management can be even in those patients who have very limited blood supply to their ventricles. All 3 patients initially had class IV HF and very low LVEF in the echocardiogram. In each patient cardiac catheterization revealed severe multivessel CAD and probable remote silent infarcts. One of the 3 patients had 100\% proximal occlusion of all 3 major epicardial coronary arteries. Despite these grave prognostic indicators, each patient experienced rapid and robust clinical improvement combined with an essentially full normalization of their left ventricular systolic function. With ongoing aggressive therapy, both the clinical and echocardiographic recovery has been sustained for years. It is well known that in patients with ischemic cardiomyopathy medical management can result in clinical improvement. To our knowledge, however, full and sustained echocardiographic recovery without $\mathrm{CABG}$ has not been previously reported.

The results of this simple case series should be interpreted with caution. In our heart failure clinic not all patients with ischemic cardiomyopathy experienced echocardiographic normalization, although the vast majority had marked clinical improvement. In addition, it is uncertain if patients who are not followed in an intensive disease management program such as ours would have similarly favorable outcomes. Our "proof of concept" case series, however, does show that even those patients who are not candidates for revascularization can potentially have excellent outcomes with medical management. In patients considered to be suboptimal candidates for $\mathrm{CABG}$, pursuing aggressive medical management first appears to be a reasonable option with consideration for revascularization if they develop angina or if they do not experience improvement in their HF and LVEF with medical management alone.

\section{References}

[1] Butler J, Fonarow GC, Gheorghiade M. Need for increased awareness and evidence-based therapies for patients hospitalized for heart failure. JAMA. 2013; 310(19): 2035-6. http://dx.doi.org/10.1001/jama.2013.282815

[2] Ng ACC, Sindone AP, Wong HSP, et al. Differences in management and outcome of ischemic and non-ischemic cardiomyopathy. Int J Cardiol. 2008; 129(2): 198-204. http://dx.doi.org/10.1016/j.ijcard.2007.07.014

[3] Killip T, Passamani E, Davis K. CASS principal investigators and associates. Coronary artery surgery study (CASS): a randomized trial of coronary bypass surgery: eight years follow-up and survival in patients with reduced ejection fraction. Circulation. 1985; 72(6 Pt2): V-102-9.

[4] Varnauskas E. Twelve-year follow-up of survival in the randomized European Coronary Surgery Study. N Engl J Med. 1988; 319(6): 332-7. http://dx.doi.org/10.1056/NEJM198808113190603

[5] Califf RM, Harrell FE Jr, Lee KL, et al. The evolution of medical and surgical therapy for coronary artery disease: a 15-year perspective. JAMA. 1989; 261(14): 2077-86. http://dx.doi.org/10.1001/jama.1989.03420140079032

[6] Elefteriades JA, Tolis G Jr, Levi E, et al. Coronary artery bypass grafting in severe left ventricular dysfunction: excellent survival with improved ejection fraction and functional state. J Am Coll Cardiol. 1993; 22(5): 1411-7. http://dx.doi.org/10.1016/0735-1097(93)90551-B

[7] O'Connor CM, Velazquez EJ, Gardner LH, et al. Comparison of coronary artery bypass grafting versus medical therapy on long-term outcome in patients with ischemic cardiomyopathy (a 25-year experience from the Duke Cardiovascular Disease Databank). Am J Cardiol. 2002; 90(2): 101-7. http://dx.doi.org/10.1016/S0002-9149(02)02429-3

[8] Velazquez EJ, Lee KL, Deja MA, et al. Coronary-artery bypass surgery in patients with left ventricular dysfunction. N Engl J Med. 2011; 364(17): 1607-16. http://dx.doi.org/10.1056/NEJMoa1100356

[9] Yancy CW, Jessup M, Bozkurt B, et al. 2013 ACCF/AHA guideline for the management of heart failure: executive summary: a report of the American College of Cardiology Foundation/American Heart Association Task Force on Practice Guidelines. J Am Coll Cardiol. 2013; 62(16): e147-239. http://dx.doi.org/10.1016/j.jacc.2013.05.019 